[Technical Paper]

\title{
Bonding Pad Fabrication for Printed Electronics Using Silver Nanoparticles
}

\author{
Makoto Nakatani, Haruyuki Nakajo, Hiroshi Saito, Masayuki Ueda, and Hideyuki Gotoh \\ Tsukuba Development Dept, R\&D Center, R\&D Company, Harima Chemicals, INC., 5-9-3 Tokodai, Tsukuba-shi, Ibaraki 300-2635, Japan
}

(Received August 30, 2013; accepted November 27, 2013)

\begin{abstract}
Silver nanoparticle paste (SNP) was demonstrated to be a promising candidate as an alternative material to conventional silver electro-plating. The sintered film of SNP in a reductive atmosphere showed excellent bonding strength equivalent to the value of the silver electro-plated surface in gold and copper wire bonding. The silver hybrid paste (SHP) composed of micro and nanoparticles has been newly developed. SHP with $40 \mu \mathrm{m}$ thickness exhibited low volume resistivity after sintering. The sintered film showed good wire bondability.
\end{abstract}

Keywords: Printed Electronics, Nanoparticle, Silver Nanoparticle Paste, Silver Hybrid Paste, Ink-jet Printing, Screen Printing, Wire Bonding

\section{Introduction}

In recent years, printed electronics technology using metal nanomaterials has attracted a great deal of attention in its applications.[1] Conventional electronic systems are traditionally fabricated using photolithography. This system requires multiple steps, time consuming processes and expensive facilities. In addition, the photolithographic process generates large volumes of hazardous waste, which damage the environment. As for printed electronics, the formation of electronic circuits and devices is possible using print technology. And it is expected in price reduction, productivity improvement, and environmental friendliness including resource saving. In particular, ink-jet printing is an attractive tool. Ink-jet technology offers numerous advantages; it is an environmentally friendly process that eliminates etching solutions, uses fewer processing steps, reduces processing time and lowers costs. Direct patterning using ink-jet printing eliminates the preparation of masks. It is a non-contact process that selectively deposits a broad range of materials onto a wide range of substrates in a drop-by-drop manner.

Recently there has been active research to develop applications by using ink-jet printing technologies such as organic TFT.[2,3] Print heads are controlled by computer. The uniform ejection of the paste droplets from the print head enables it to deliver precise amounts of paste to specified positions on a substrate. The paste, containing a high amount of nanoparticles, should be ejected by piezoelectric ink-jet nozzles to apply the metal particles. The paste should have the physical and rheological properties of liquid for ink-jet printing.

The unique physical property of metal nanoparticles can be derived due to a large amount of atoms on the surface of the nanoparticles. The melting point of metal nanoparticles can be dramatically decreased. This behavior is the result of the property known as quantum size effect. The large depression of melting point occurs in the case of gold nanoparticles less than $5 \mathrm{~nm}$ in diameter.[4] Metal nanoparticle paste can be printed by ink-jet and then converted into bulk metal after sintering. Therefore, metal nanoparticles can be applied to organic substrates and easily-oxidized materials, such as copper lead frame.

The silver electro-plating process is the conventional method for the formation of bonding pads on a copper lead frame. Gold wires are used to connect to this silver pad of the die pad. The bonding pad pitch on copper lead frames is getting finer in recent years. The pad formation by a silver electro-plating could not satisfy this requirement. Direct pad formation by ink-jet printing using silver nanoparticle paste (SNP) has some advantages. This process has several environmentally friendly benefits compared with a silver electro-plating, because the chemical compounds such as $\mathrm{AgCN}$ are not needed for ink-jet printing. In the silver electro-plating process, waste of silver 
Table 1 Properties of silver pastes.

\begin{tabular}{l|c|c|c}
\hline \multicolumn{1}{c|}{ Item } & $\begin{array}{c}\text { Silver nanoparticle paste } \\
\text { (SNP) }\end{array}$ & $\begin{array}{c}\text { Silver hybrid paste } \\
\text { (SHP) }\end{array}$ & $\begin{array}{c}\text { Silver nanoparticle paste-2 } \\
(\text { SNP-2) }\end{array}$ \\
\hline Appearance & Dark blue & Gray & Dark blue \\
\hline Metal particle & Silver nanoparticle & $\begin{array}{c}\text { Silver nanoparticle, Silver } \\
\text { microparticle }\end{array}$ & Silver narticle \\
\hline Metal content & $62-67$ mass $\%$ & $83-88$ mass $\%$ & mass\% \\
\hline Solvent & Tetradecane & 1-Decanol & Tetradecane \\
\hline Viscosity & $7-11 \mathrm{mPa} \cdot \mathrm{s}$ & $20-50 \mathrm{~Pa} \cdot \mathrm{s}$ & $80-120 \mathrm{~Pa} \cdot \mathrm{s}$ \\
\hline Printing process & Ink-jet printing & Screen printing & Screen printing \\
\hline
\end{tabular}

electro-plating solution must be treated to recover silver. The amount of silver consumed by ink-jet printing is much less compared with the electro-plating method because the required amount of SNP can be precisely applied to the place where required. Fine pitch pad formation is also a great feature.

This report explains the development of SNP for practical use, primarily in ink-jet printing technology as an alternative to silver electro-plating. In order to correspond with various printing methods, a silver hybrid paste (SHP) was newly developed. Sintering conditions and inner structure are also described.

\section{Experimental}

\subsection{Silver pastes}

The feature of silver pastes is summarized in Table 1. Silver nanoparticle paste (SNP) is suitable for ink-jet printing because the viscosity is very low, around $10 \mathrm{mPa} \cdot \mathrm{s}$, in spite of the metal content up to 65 mass\%. Silver hybrid paste (SHP) for screen printing consists of micro and nanoparticles. Silver nanoparticle paste-2 (SNP-2) for screen printing consists of only nanoparticles.

The volume resistivity $(\rho)$ of silver film was calculated by Eq. (1). Electrical resistance was measured using the four-terminal method.

$$
\begin{aligned}
& \rho=R \times A \times \ell^{-1} \\
& R \text {; Electrical resistance of the film }(\Omega) \\
& A ; \text { Cross-sectional area of the film }\left(\mathrm{cm}^{2}\right) \\
& \ell ; \text { Length of the film }(\mathrm{cm})
\end{aligned}
$$

\subsection{Wire bonding}

The bonding pads $\left(200 \mu \mathrm{m}^{2}\right)$ were fabricated using printing process and sintering process on a copper lead frame. Figure 1 (a) shows the semiautomatic wire bonder (HB16, TPT) used in the experiment. To measure average pull strength, 10 wires bonded on the silver film were pulled by a hook with a load meter, as shown in Fig. 1 (b).

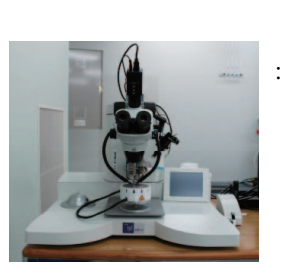

(a) Wire bonder

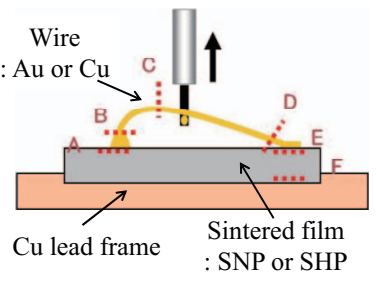

(b) Pull test of bonded wire and breakage mode

Fig. 1 Wire bonding and bondability test.

\section{Result and Discussion}

\subsection{Bonding pad fabrication in ink-jet printing using silver nanoparticle paste (SNP)}

Silver nanoparticle paste (SNP) consists of silver nanoparticles that have a narrow size distribution. Figure 2 shows a TEM image of silver nanoparticles used in SNP. The nanoparticles were produced by a chemical reaction method in liquid phase. Nanoparticles covered with dispersants are highly stable. Particle size distribution of silver nanoparticles is shown in Fig. 3. The sizes of nanoparticles are quite uniform with an average diameter of $12 \mathrm{~nm}$.

The sintering temperature greatly affects the elimination and decomposition process of the dispersant. These processes are simply activated by heating in an air atmosphere. Change of volume resistivity by sintering temperature is indicated in Fig. 4 (a). The volume resistivity of the sintered SNP is very low $(1.9 \mu \Omega \cdot \mathrm{cm})$, and close to that of the bulk silver $(1.6 \mu \Omega \cdot \mathrm{cm})$. The cross-sectional SIM image of sintered SNP at a sintering process of $220^{\circ} \mathrm{C}$ for $60 \mathrm{~min}$ in an air atmosphere is shown in Fig. 4 (b). Nanoparticles were successfully sintered and formed large silver grains were obtained.

Table 2 shows wire bondability of SNP and silver electro-plating on a copper lead frame under various conditions. Firstly, wire bonding using a gold wire on sintered film of SNP was done. The bonding pad $\left(200 \mu \mathrm{m}^{2}\right)$ was printed using ink-jet printing and sintered at $230^{\circ} \mathrm{C}$ for 60 
min in an air atmosphere on a copper lead frame. At each test point, wide variations of the pull strength were observed. In addition, breakage mode also varied. The mode was B, D, E or F. In comparison, the electro-plated pad has an average pull strength of 12.1 gf. Every wire

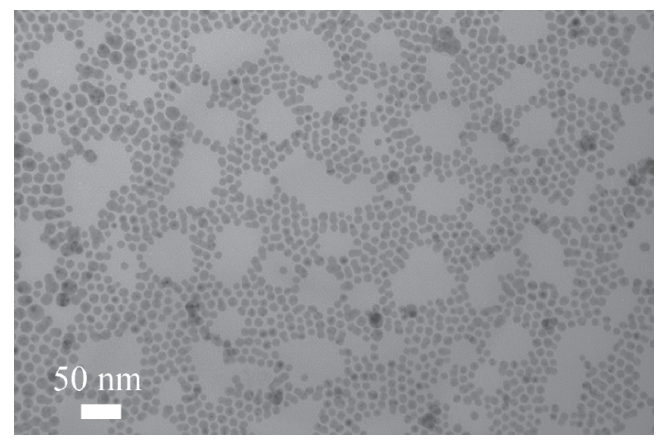

Fig. 2 TEM image of silver nanoparticles.

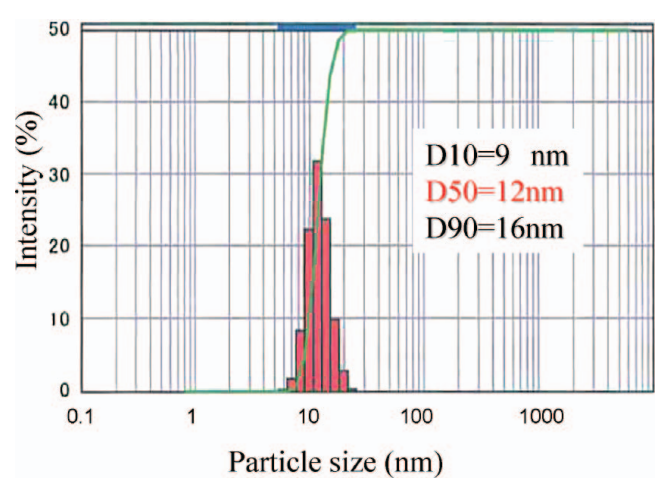

Fig. 3 Particle size distribution of silver nanoparticles.

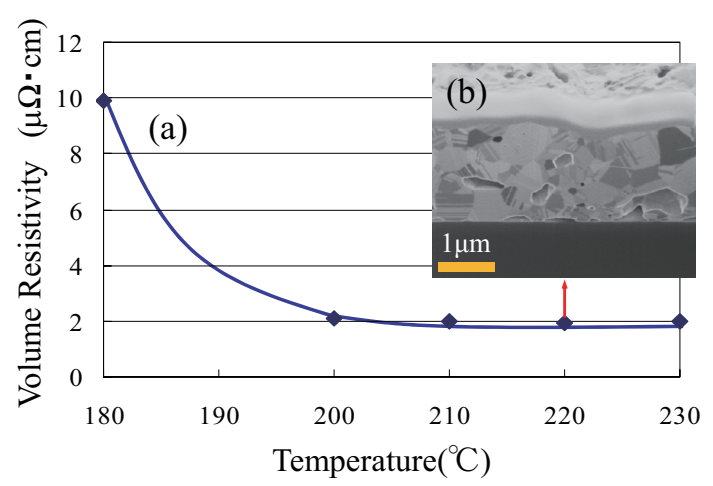

Fig. 4 (a) Relationship between sintering temperature and resistivity on SNP, (b) Cross-sectional image of sintered SNP. breakage occurred at the middle of the wire (mode $\mathrm{C}$ ).

SNP was sintered at $300^{\circ} \mathrm{C}$ for $30 \mathrm{~min}$ in a reductive atmosphere $\left(\mathrm{N}_{2} / 3 \% \mathrm{H}_{2}\right)$ and a wire bonding was attempted. At each test point, an average pull strength of more than $11 \mathrm{gf}$, equivalent to the value of the silver electro-plated surface was obtained. Breakage mode on silver pads became stable; almost all of the wire breakage occurred at the middle of the wire (mode $\mathrm{C}$ ).

In recent years, due to the increase in gold wire prices, Pd-coated copper wire has become an attractive way to control costs. [5] In this process, nitrogen gas can be used as a non-oxidizing gas during ball formation. Pd-coated copper wire bonding on a sintered film of SNP was achieved. An average pull strength of more than $13 \mathrm{gf}$ was obtained.

The cross-sectional image of sintered SNP at a sintering temperature of $230^{\circ} \mathrm{C}$ in an air atmosphere is shown in Fig. 5 (a). A layer of oxidation was observed between the sintered film and a copper lead frame. The layer of oxidation was analyzed by EDX (Table 3). Due to this oxidized layer, bonding strengths were weakened. The cross-sectional image of sintered SNP at a sintering temperature of $300^{\circ} \mathrm{C}$ in a reductive atmosphere is shown in Fig. 5 (b). In a reductive atmosphere, oxidized layer was not observed between the sintered film and a copper lead frame.

Sintered film of SNP showed excellent bonding strength, equivalent to the value of the silver electro-plated surface. SNP has a potential to possibly replace a silver electro-plating.
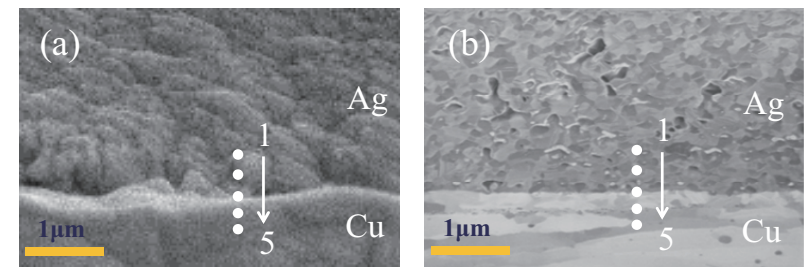

Fig. 5 EDX analyses points of the interface of silver / copper; (a) Sintered at $230^{\circ} \mathrm{C}$ in an air atmosphere, (b) Sintered at $300^{\circ} \mathrm{C}$ in a reductive atmosphere.

Table 2 Wire bondability of SNP and silver electro-plating.

\begin{tabular}{lccrccc}
\hline \multirow{2}{*}{ Silver film } & $\begin{array}{c}\text { Sintering } \\
\text { atmosphere }\end{array}$ & Wire & \multicolumn{3}{c}{ Strength, gf } & \multirow{2}{*}{ Breakage } \\
& Air & $\mathrm{Au}$ & 6.3 & 15.1 & 10.2 & B, D, E, F \\
\hline SNP & & $\mathrm{Au}$ & 11.8 & 14.2 & 12.1 & $\mathrm{C}$ \\
\hline Silver & - & $\mathrm{Cu}$ & 12.2 & 14.4 & 13.2 & B, C \\
electro-plating & & $\mathrm{Au}$ & 9.9 & 14.1 & 11.4 & $\mathrm{C}$ \\
\hline \multirow{3}{*}{ SNP } & \multirow{2}{*}{$3 \% \mathrm{H}_{2} / \mathrm{N}_{2}$} & $\mathrm{Cu}$ & 11.7 & 15.6 & 13.1 & B, C \\
\hline
\end{tabular}


Table 3 EDX quantitative analysis.

\begin{tabular}{c|c|c|c|c|c|c}
\hline \multirow{2}{*}{ No. } & \multicolumn{3}{|c|}{ Fig. 5 (a) } & \multicolumn{3}{c}{ Fig. 5 (b) } \\
\cline { 2 - 7 } & $\begin{array}{c}\mathrm{Ag} \\
(\mathrm{mass} \%)\end{array}$ & $\begin{array}{c}\mathrm{Cu} \\
(\mathrm{mass} \%)\end{array}$ & $\begin{array}{c}\mathrm{O} \\
(\mathrm{mass} \%)\end{array}$ & $\begin{array}{c}\mathrm{Ag} \\
(\mathrm{mass} \%)\end{array}$ & $\begin{array}{c}\mathrm{Cu} \\
(\mathrm{mass} \%)\end{array}$ & $\begin{array}{c}\mathrm{O} \\
(\mathrm{mass} \%)\end{array}$ \\
\hline 1 & 92.1 & 5.18 & 2.68 & 99.2 & 0.84 & 0 \\
\hline 2 & 91.6 & 6.22 & 2.18 & 78.8 & 22.2 & 0 \\
\hline 3 & 74.2 & 23.9 & 1.94 & 23.5 & 76.5 & 0 \\
\hline 4 & 5.13 & 90.9 & 3.98 & 0.71 & 99.3 & 0 \\
\hline 5 & 0 & 95.7 & 4.26 & 0 & 100 & 0 \\
\hline
\end{tabular}

\subsection{Bonding pad fabrication in screen printing using silver hybrid paste (SHP)}

In order to correspond with various printing methods, especially screen printing, silver hybrid paste (SHP) composed of micro and nanoparticles has been newly developed.[6] Figure 6 shows the result of a screen printing using SHP. Screen printing using SHP was capable of producing lines with as thick as $100 \mu \mathrm{m}$. SHP can correspond with other printing methods by optimizing its viscosity, for instance, a dispenser printing or a pin transcription printing.

SHP was sintered for $60 \mathrm{~min}$ in an air atmosphere. Figure 7 shows a surface structure of sintered film. A higher temperature accelerates grain growth. At a sintering temperature of $150^{\circ} \mathrm{C}$, the grain growth of silver particles was not observed. At over $180^{\circ} \mathrm{C}$, grains grew to a large size and the number of micro pores were greatly reduced. $\mathrm{A}$ volume resistivity of silver film sintered at $180^{\circ} \mathrm{C}$ is indicated in Fig. 8, showing dependence on the film thickness. SHP kept a low volume resistivity around $4 \mu \Omega \cdot \mathrm{cm}$, close to that of the bulk silver, regardless of film thickness. On the other hand, silver nanoparticle paste-2 (SNP-2) for screen printing composed of only nanoparticles, volume resistivity of sintered film increased depending on film thickness. The inner structure of sintered film was observed. SHP's inner structure with $40 \mu \mathrm{m}$ thickness sintered at $180^{\circ} \mathrm{C}$ is indicated in Fig. 9 (a). The grains grew greatly, and a porous structure was not observed. On the other hand, SNP-2's inner structure with $35 \mu$ m thickness sintered at $230^{\circ} \mathrm{C}$ was porous structure and the grain growth of silver particles was not observed (Fig. 9 (b)). The difference of the volume resistivity of the each paste was caused by a difference of the inner structure.

Table 4 shows wire bondability of SHP on a copper lead frame. SHP was sintered at $300^{\circ} \mathrm{C}$ for $30 \mathrm{~min}$ in a reductive atmosphere $\left(\mathrm{N}_{2} / 3 \% \mathrm{H}_{2}\right)$ and a gold wire bonding was attempted. SHP showed an excellent bonding strength (14 gf) equivalent to the value of silver electro-plating.

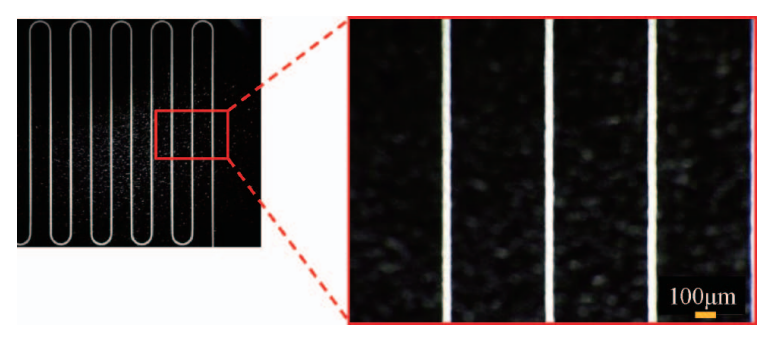

Fig. 6 Screen printed patterns of SHP.

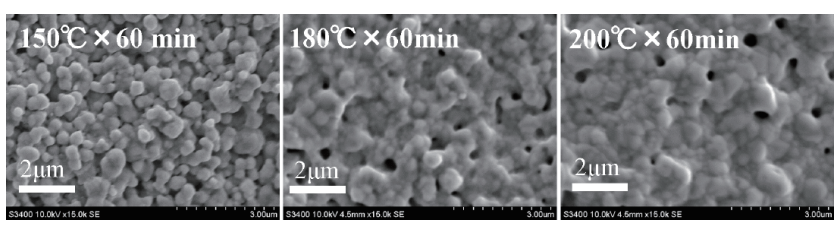

Fig. 7 SEM image; Surface of sintered state with sintering temperature.

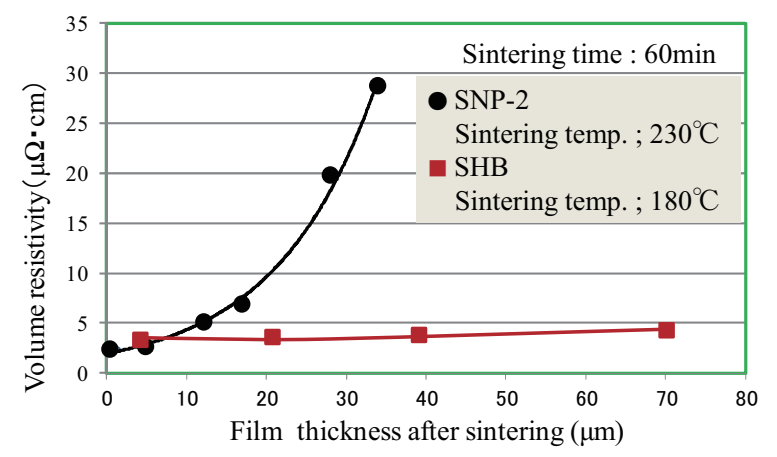

Fig. 8 Change of volume resistivity by sintering conditions.
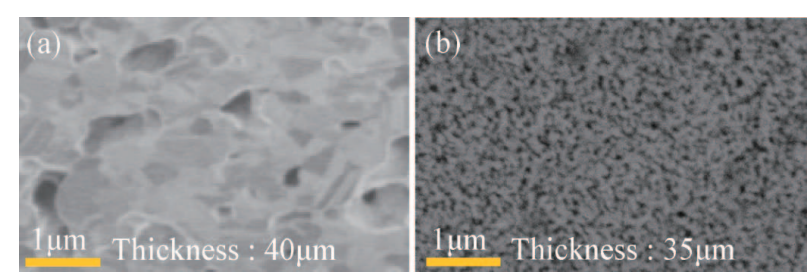

Fig. 9 Cross-sectional images; (a) SHP, (b) SNP-2.

Table 4 Wire bondability of SHP.

\begin{tabular}{lcccccc}
\hline $\begin{array}{c}\text { Silver } \\
\text { film }\end{array}$ & $\begin{array}{c}\text { Sintering } \\
\text { atmosphere }\end{array}$ & \multicolumn{4}{c}{ Wire } & \multicolumn{3}{c}{ Strength, gf } & Breakage \\
Min. & Max. & Avg. & mode \\
\hline SHP & $3 \% \mathrm{H}_{2} / \mathrm{N}_{2}$ & Au & 11.6 & 16.5 & 14.3 & B, C \\
\hline
\end{tabular}




\section{Conclusions}

Ink-jet printing using silver nanoparticle paste (SNP) can be applied to printed electronics. The inner structure of SNP was observed. SNP converted into bulk silver when sintered at over $220^{\circ} \mathrm{C}$. A good wire bondability was obtained for the sintered $\mathrm{SNP}$ at $300^{\circ} \mathrm{C}$ in a reductive atmosphere. SNP was applied to copper lead frame and we propose that the material be used as a replacement for silver electro-plating. Silver hybrid paste (SHP) was composed of micro and nanoparticles was newly developed. SHP is suitable for screen printing. Sintered film of SHP showed low volume resistivity close to bulk silver when sintered at over $180^{\circ} \mathrm{C}$, regardless of film thickness. The sintered film showed good wire bondability.

\section{References}

[1] S. B. Fuller, E. J. Eilhelm, and J. Jacobson, "Ink-jet Printed Nanoparticle Microelectromechanical Systems,” Journal of Microelectrochanical Systems, Vol. 11, No. 1, pp. 1213-1220, 2002.

[2] Y. Noguchi, T. Sekitani, T. Yokota, and T. Someya, "Direct Inkjet Printing of Silver Electrodes on Organic Semiconductors for Thin-film Transistors with Top Contact Geometry,” Applied Physics Letters, Vol. 93, 043303, 2008.
[3] K. Fukuda, T. Sekine, Y. Kobayashi, Y. Takeda, M. Shimizu, N. Yamashita, D. Kumaki, M. Itoh, M. Nagaoka, T. Toda, S. Saito, M. Kurihara, M. Sakamoto, and S. Tokito, “Organic Integrated Circuits Using Room-temperature Sintered Silver Nanoparticles as Printed Electrodes," Organic Electronics, Vol. 13, pp. 3296-3301, 2012.

[4] P. Buffat and J.-P. Borel, "Size Effect on the Melting Temperature of Gold Particles," Physical Review A, Vol. 13, No. 6, pp. 2287-2298, 1976.

[5] M. Onodera, Y. Shinma, K. Meguro, J. Tanaka, and J. Kasai, "Wire Bonding Using Pd Plated Cu Wire," Journal of Japan Institute of Electronics Packaging, Vol. 11, No. 6, pp. 444-450, 2008.

[6] H. Saito, M. Ueda, and N. Terada, "Development and Application of Hybrid Silver Paste,” 18th Symposium on Microjoining and Assembly Technology in Electronics, Vol. 18, pp. 163-166, 2012.

\author{
Makoto Nakatani \\ Haruyuki Nakajo \\ Hiroshi Saito \\ Masayuki Ueda \\ Hideyuki Gotoh
}

